\title{
Dilemas para a Implementação de Programas de Incentivo Atrelados a Desempenho em Segurança Pública
}

\author{
Marchesini da Costa, Marcelo; Cabral, Sandro; Macchione Saes, Paula \\ Dilemas para a Implementação de Programas de Incentivo Atrelados a Desempenho em Segurança Pública \\ Administração Pública e Gestão Social, vol. 12, núm. 4, 2020 \\ Universidade Federal de Viçosa, Brasil \\ Disponible en: http://www.redalyc.org/articulo.oa?id=351564289020
}

Esta obra está bajo una Licencia Creative Commons Atribución-NoComercial-SinDerivar 3.0 Internacional. 


\section{Dilemas para a Implementação de Programas de Incentivo Atrelados a Desempenho em Segurança Pública}

Dilemmas for Implementing Incentive Programs Linked to Public Security Performance

Dilemas para Implementar Programas de Incentivo Vinculados al Desempeño de la Securidad Pública

Marcelo Marchesini da Costa

Insper, Brasil

Redalyc: http://www.redalyc.org/articulo.oa?

Marcelomc5@insper.edu.br id $=351564289020$

Sandro Cabral

Insper, Brasil

Sandroc2@insper.edu.br

Paula Macchione Saes

Universidade Estadual de Campinas, Brasil

paulinhasaes@gmail.com

Recepción: 28 Agosto 2018

Aprobación: 16 Marzo 2020

Publicación: 01 Octubre 2020

Palavras chave: Incentivo, desempenho, polícia

KEYWORDS: Incentive, performance, police

Palabras ClaVe: Incentivo, desempeño, policia

\section{INTRODUÇÃO}

Este caso de ensino introduz dilemas enfrentados por uma liderança governamental da área de segurança pública ao tentar estabelecer um sistema de incentivo. Apesar do grande conhecimento acumulado sobre sistemas de incentivo, ainda restam muitos questionamentos sobre quais são as melhores práticas e como adaptá-las para diferentes situações específicas. Também se sabe que há muitos problemas que podem ocorrer em função de uma má aplicação de um sistema de incentivos.

Especificamente, a atividade policial enfrenta inúmeras dificuldades. Além de restrições orçamentárias e resistências a uma atuação conjunta de diferentes forças policiais, o contexto da sociedade, com crises econômicas e desemprego, por exemplo, pode levar ao aumento dos índices de criminalidade, independente de aumento do esforço policial. Enquanto o esforço de um funcionário de uma linha de produção se reflete quase diretamente no seu número de peças produzidas, o esforço de um policial pode não se refletir facilmente na redução de crimes. Sendo assim, escolhas realizadas por gestores da área não são suficientes para atingir os resultados desejados nos indicadores finalísticos. A despeito disso, os desafios da área exigem ações gerenciais rápidas e inovadoras. Ao colocar os alunos no papel de um gestor recém-empossado em um governo estadual fictício, utilizando referências de experiências reais, este caso propõe uma série de reflexões sobre mensuração de desempenho, incentivos e governança no setor público.

O caso está estruturado com uma descrição da situação, a problematização de alguns aspectos centrais e um conjunto de anexos, dentre os quais o último é a nota de ensino que relaciona os principais teóricos que podem ser explorados durante a aplicação do caso. 


\section{DESCRIÇÃO DA SITUAÇÃo}

Após décadas de experiência na Polícia Militar do Estado de Santa Clara, o coronel Evair das Palmeiras foi convidado para comandar a Secretaria de Segurança Pública do estado no início de 2019. Apesar de feliz com a confiança depositada pela governadora e de sentir-se pronto para novo desafio, o coronel estava preocupado. De fato, ao observar a situação da segurança pública do estado do Rio de Janeiro em 2017, que resultou em uma intervenção federal na área (ver anexo 1), o coronel não considerava que seu estado estava em uma situação muito melhor. Dilemas de gestão comuns aos gestores da área de segurança pública em diversos estados persistiam em Santa Clara. Afinal, como reduzir os índices de criminalidade? Quais os principais pontos a serem atacados para dar respostas para a população? Como motivar as forças policiais para que cumpram suas funções dentro da lei, ao mesmo tempo atendendo aos anseios da sociedade? Em sua nova função, essas eram algumas das questões que passaram a acompanhar o coronel Evair, inclusive em seus raros momentos de lazer.

Estudioso do tema e com décadas de experiência na área, Evair sabia que não existem soluções mágicas para resolver problemas complexos. Sua primeira ação foi examinar criticamente as diversas experiências de gestão testadas na área de segurança pública ao longo do tempo. De fato, nas últimas décadas, diversas inciativas foram implantadas e igualmente descontinuadas na segurança pública, não raro sem avaliação criteriosa, tais como programas de policiamento comunitário e ações voltadas à maior integração entre as diferentes forças policiais. Diante da falta de uma cultura de avaliação de políticas públicas, algo que não é exclusivo da área de segurança, gestores, políticos e população, ao fim e ao cabo, não possuem clareza sobre os fatores de sucesso, ou fracasso, das práticas experimentadas e em curso.

Uma medida em particular, no entanto, há tempos despertava interesse no coronel Evair. Alguns anos antes da intervenção federal das forças armadas, o próprio estado do Rio de Janeiro havia adotado um programa de mensuração de desempenho e pagamento de bônus a policiais atrelado a resultados. Nesse programa, recompensas eram pagas a policiais que atingiam as metas semestrais estipuladas pela Secretaria de Segurança Pública. O programa, chamado Sistema de Metas e Acompanhamento de Resultados (SIM), recebeu elogios nos primeiros anos e foi replicado, com algumas mudanças, por outros estados brasileiros. Embora os índices de criminalidade tenham oscilado (ver Figura 1) avaliações independentes[i] mostram que o SIM apresentou, entre 2009 e 2015, efeitos benéficos em áreas geográficas nas quais os policiais civis e militares atuam em regiões elegíveis ao bônus.

Evair acreditava que um programa de incentivos poderia motivar os policiais, promovendo maior esforço e melhores resultados. Por outro lado, em função das dificuldades inerentes à implementação do programa, sobretudo no que tange ao apoio de atores-chave do estado, a experiência do Rio de Janeiro não parecia ter bons resultados no longo prazo. Era preciso investigar mais a fundo o funcionamento desse tipo de iniciativa para determinar suas possibilidades para o estado de Santa Clara.

\section{Alguns Desafios EM SEguranÇA PÚBlicA}

A violência é um fenômeno com múltiplas causas e que pode estar associada a diversos fatores, tais como desemprego, padrões de urbanização, escolaridade, distribuição de renda, dentre outros[ii]. Tais condições variam no espaço e no tempo. Ou seja, os homicídios podem aumentar porque a pobreza está crescendo, por exemplo, mesmo que a polícia esteja realizando todas as ações ao seu alcance para reduzir o crime. Além disso, a sensação de insegurança nem sempre acompanha os índices reais de criminalidade. A quantidade de reportagens e a abordagem da mídia para determinados crimes, por exemplo, influenciam o quanto a população se sente insegura e quanto de apoio há para diferentes condutas policiais. Outro dado relevante para a ação policial é que os índices de criminalidade não avançam de maneira uniforme. $\mathrm{O}$ número de 
homicídios pode estar diminuindo enquanto os sequestros e o número de ações conjuntas entre as forças policiais aumentam.

Observando esses dados sobre a experiência do Rio de Janeiro, Evair ficou ainda mais confuso. Quais seriam as medidas relevantes da ação policial? Era preciso ir além da análise dos dados e conversar com conhecedores da área de segurança e de sistemas de metas e incentivos para forças policiais.

A primeira pessoa com quem Evair conversou foi uma amiga dos tempos de colégio, Ana Duarte, que havia sido assessora do governador do estado do Rio de Janeiro em 2007, no primeiro ano daquela gestão. A equipe dirigente da segurança pública estadual, já em 2007, percebia que a avaliação do governo por parte da opinião pública dependeria em grande medida da redução da violência e da melhoria da sensação de segurança nas ruas. Ana Duarte afirmou:

A segurança pública é um terreno muito complicado. Havia muitas indicações políticas para os cargos de comando e muitas pessoas sendo condecoradas sem necessariamente apresentar resultados. Queríamos acabar com aquelas práticas, reconhecendo os policiais de acordo com o seu mérito. Seguindo as boas práticas do setor privado, resolvemos arriscar o estabelecimento de metas e premiações por resultado, mesmo sabendo que isso é algo pouco comum no governo.

Os desafios para estabelecer um programa de incentivos não eram poucos. Além da falta de costume com metas e remuneração variável, a segurança pública nos estados brasileiros é função compartilhada das Polícias Militar e Civil. Em termos gerais, a Polícia Militar é responsável pelo policiamento ostensivo nas ruas, enquanto a Polícia Civil é responsável pelas investigações criminais. Em que pese o histórico nem sempre harmonioso e circundado de conflitos (ver Anexo 2), na Secretaria de Segurança Pública Evair tentaria promover o trabalho integrado da Polícia Militar e da Polícia Civil, apesar de saber que cada uma dessas organizações tem uma longa trajetória, práticas cristalizadas, com estruturas de carreira e características bastante particulares, além de terem tradição de trabalhar de forma isolada, pouco integrada e com dinâmicas de rivalidade bem acentuadas. Essas diferenças o coronel conhecia bem, mas, ainda assim, Evair não desistiu da ideia de promover uma ação integrada das polícias.

\section{POR ONDE COMEÇAR?}

A princípio, Evair considerou que homicídios e roubos de rua eram indicadores que atemorizam a população, geram sensação de insegurança e deveriam ser priorizados. No entanto, ao comentar com a sua esposa que pretendia utilizar somente esses indicadores, Evair foi surpreendido com a seguinte reação da sua companheira:

. Não tem nenhuma meta para a redução de crimes contra a mulher? Isso não é importante? E o roubo de casas? Minha amiga Elvira ficou três horas com arma na cabeça enquanto os bandidos limpavam a casa dela. Isso é sofrimento!

Logo na sequência, ao comentar esse episódio com um colega da Polícia Militar, Evair ouviu o seguinte comentário:

- Não sei se concordo com a sua esposa, coronel, mas definir metas com base nos crimes não me parece uma boa ideia. Quem comete crimes são criminosos! Acho que as metas deveriam focar no que podemos efetivamente fazer, como número de prisões, apreensões de drogas, armas e coisas do tipo.

Outro coronel, amigo de Evair, dos tempos de academia, foi mais enfático:

- Evair, nossa missão é melhorar a percepção de segurança das pessoas. O sistema de metas tem que premiar a melhora desse indicador!

Evair ficou bastante irritado com aqueles comentários. O que eles queriam? Metas para tudo? Como gerir um sistema desses? Como lidar com as divergências internas? E se os crimes continuassem aumentando em algumas áreas e não em outras, como seria possível justificar o pagamento de bônus aos policiais? Como 
convencer o Secretário da Fazenda, refratário a qualquer gasto adicional, de que vale a pena alocar parte do orçamento sem garantia de contrapartida?

\section{Avaliar quem e como?}

Além de definir quais seriam as prioridades, um sistema de avaliação de desempenho para a segurança pública enfrentaria grandes desafios operacionais. A avaliação deve ser feita com base em resultados individuais ou de grupos de policiais? Nesse último caso, quem estaria em avaliação? Policiais que estão na rua? Da mesma corporação? E as áreas de suporte? Como dividir o bônus? Como articular as ações? As metas seriam as mesmas para todos os policiais? Como calculá-las? Como medir a contribuição de unidades especializadas, como cavalaria e tropa de choque? Alguém ficaria de fora do sistema?

Novamente Evair recorreu à análise da experiência fluminense para apoiar a sua tomada de decisão. O Rio de Janeiro criou Áreas Integradas de Segurança Pública (AISPs) para apoiar a implementação do SIM (ver Figura 2). Naquele estado, inicialmente optou-se por metas lineares para todas as AISPs, independentemente de suas características. Assim, propunha-se, por exemplo, uma redução de $5 \%$ na taxa de homicídio para todas as AISPs, independente do patamar inicial de uma área ser extremamente elevado e de outra ser muito baixo. Isso gerava queixas como as que o coronel Evair ouviu de um colega seu que trabalhou no interior do Rio de Janeiro:

- Quando colocavam uma mesma meta para todas as áreas, era uma baita injustiça! Reduzir em 10\% o número de homicídios na área do Complexo do Alemão é uma coisa, mas reduzir em $10 \%$ o número de homicídios em municípios do interior, onde que ocorrem um ou dois homicídios por ano, é quase impossível!

Eventualmente, o Rio de Janeiro passou a definir metas considerando a realidade de cada uma das AISPs. No entanto, os questionamentos continuavam, dessa vez voltados a outro ponto, a periodicidade das metas, conforme colocado por um colega comandante de batalhão no Rio de Janeiro:

- Em seis meses é muito difícil usar as metas de forma efetiva. As ações são de longo prazo. O reflexo não se dá na hora. Precisamos de mais tempo para ser avaliados.

Por fim, Evair tinha dúvidas sobre a fidedignidade dos dados. Sem registros confiáveis seria impossível implementar um sistema de incentivos baseado em desempenho. Relatos de registros ocultados ou adulterados não eram incomuns na segurança pública. Como convencer a Assembleia Legislativa e o pessoal de finanças do estado com bases de dados frágeis, sobretudo quando se quer pagar premiações variáveis agressivas?

\section{O QUE FAZER?}

Depois de consultar vários colegas, Evair ainda continuava com a impressão de que poderia desenhar um sistema de metas para o estado de Santa Clara.

Restavam algumas dúvidas importantes sobre a efetividade do programa, sobretudo no que tange à garantia de geração de valor público a partir do programa. Por mais que o sistema premie os vencedores do torneio, o que fazer com os perdedores? Dados do Rio de Janeiro mostravam que nem todas as unidades batiam as metas (Figura 3) e isso poderia ser motivo de preocupação, pois ao longo de mais de dez semestres do programa fluminense, algumas unidades bateram as metas poucas vezes.

Quinze dias após sua nomeação como Secretário de Segurança de Santa Clara, Evair precisava definir se iria adotar um sistema de metas e premiação aos policias do seu estado. Os próprios policiais, as organizações da sociedade civil que trabalham com segurança pública e mesmo a mídia cobravam por uma definição. $\mathrm{O}$ lado bom é que, por ser considerada área prioritária, o aumento do orçamento da segurança pública garantiria recursos modestos, mas estáveis, para que a medida fosse implementada. Seria o caso de propor à governadora um sistema de incentivos para os policiais de Santa Clara?

Quanto mais Evair pensava e estudava sobre o tema, maiores eram suas dúvidas. 


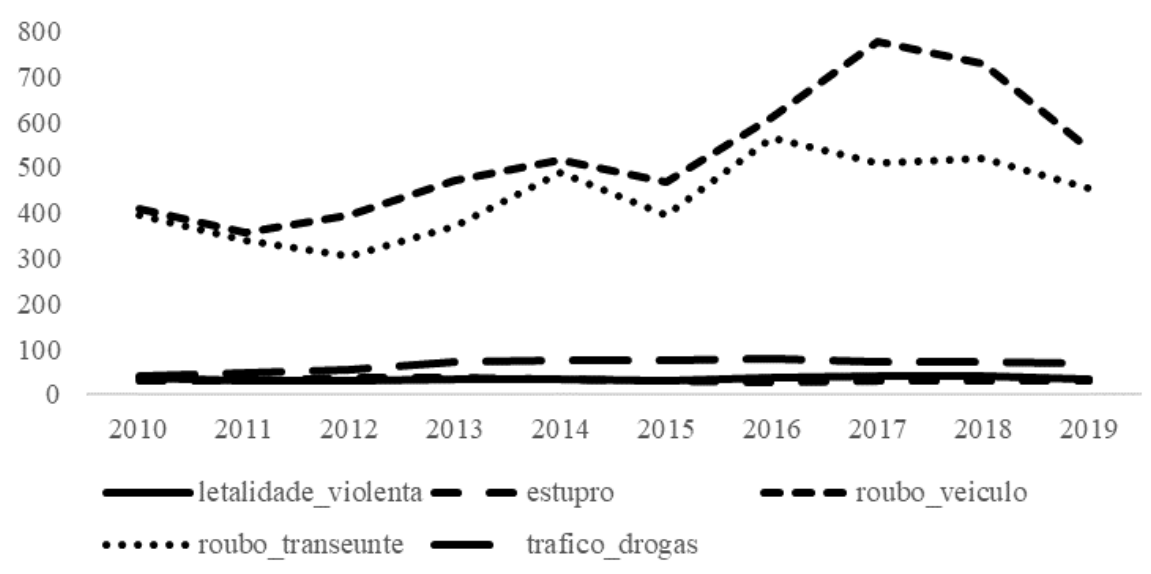

\section{FIGURA 1}

Oscilação dos Indicadores Criminais do Rio de Janeiro

Fonte: Elaborado pelos autores com base em dados do Instituto de Segurança Pública do Rio de Janeiro (disponível em http://www.ispdados.rj.gov.br/).

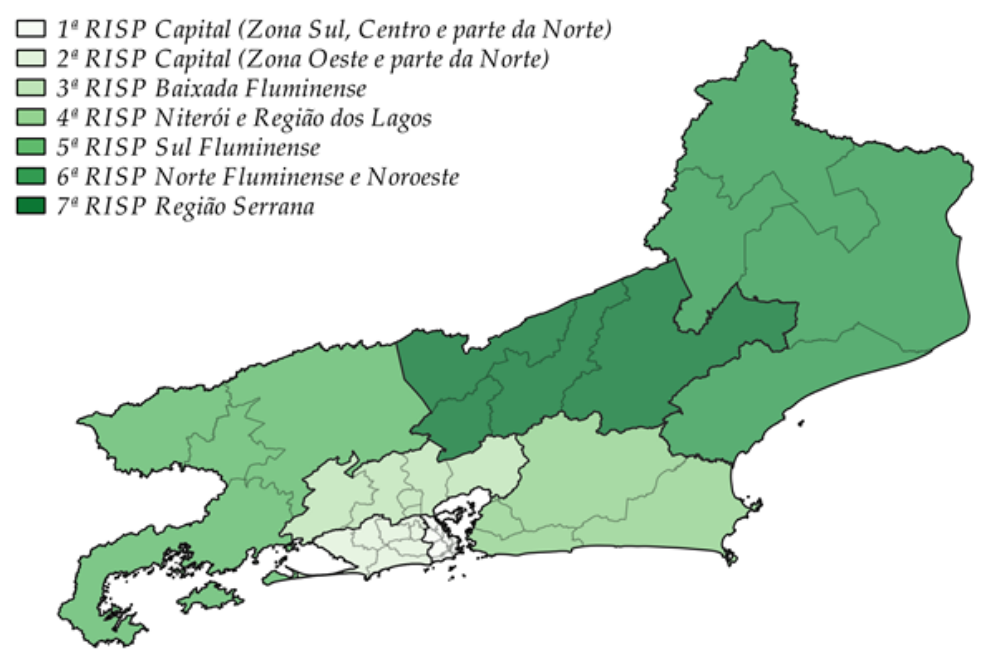

FIGURA 2

Regiões e Áreas Integradas de Segurança Pública no Rio de Janeiro Fonte: Elaborado pelos autores com base em dados do Instituto de Segurança Pública do Rio de Janeiro (disponível em http://www.ispdados.rj.gov.br/). 


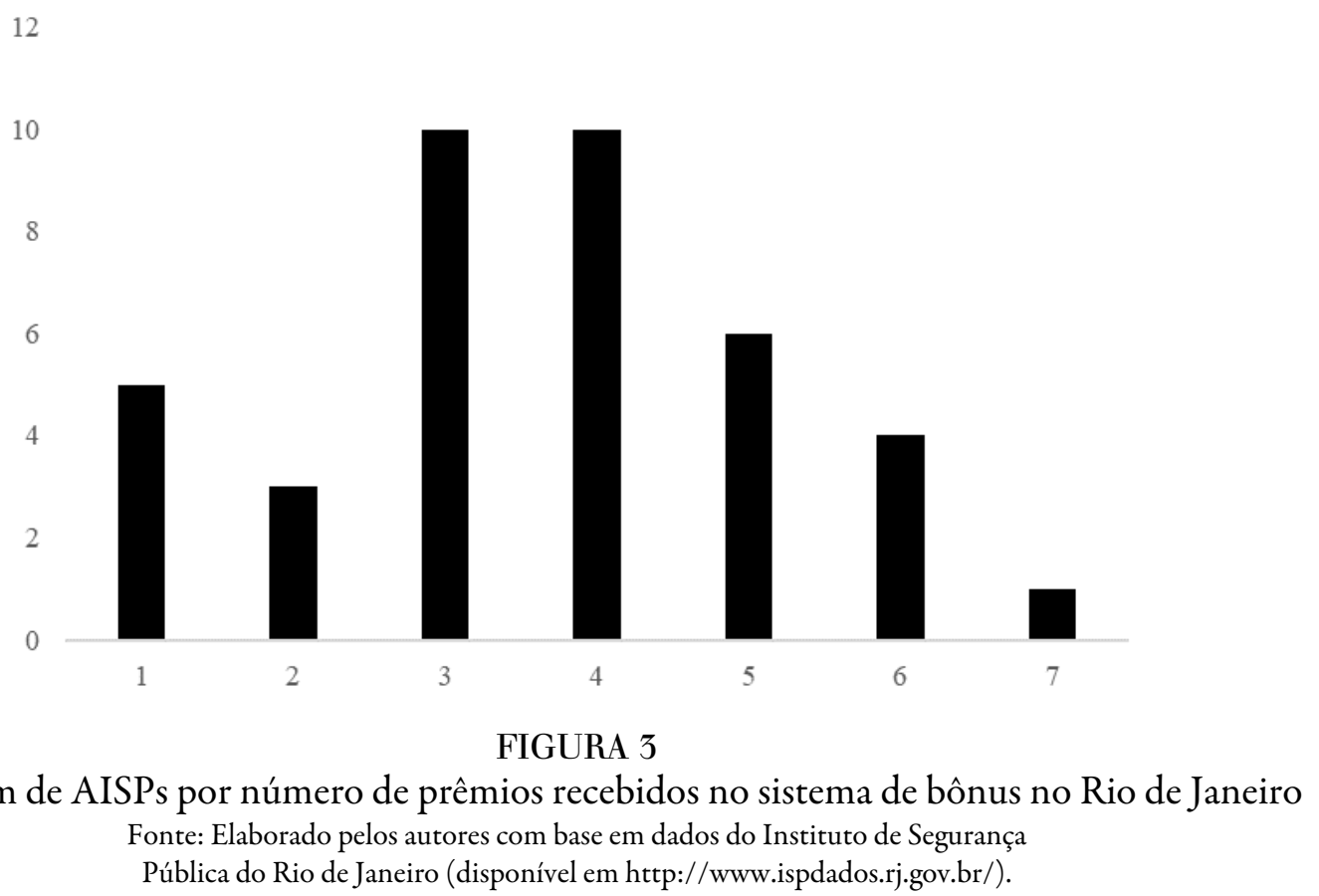

\section{Anexo 1 - Notícia Sobre intervenção na SEguranÇa do Rio de Janeiro}

Temer assina decreto de intervenção federal na segurança do Rio de Janeiro[iii]

O presidente Michel Temer assinou nesta sexta-feira (16), no Palácio do Planalto, o decreto de intervenção federal na segurança pública no estado do Rio de Janeiro.

O decreto chegou à Câmara dos Deputados na tarde desta sexta e foi protocolado por um funcionário da Casa Civil na Primeira Secretaria da Câmara.

A medida prevê que o general do Exército Walter Souza Braga Netto, do Comando Militar do Leste, será o interventor no estado. Ele assume até o dia 31 de dezembro de 2018 a responsabilidade do comando da Secretaria de Segurança, Polícias Civil e Militar, Corpo de Bombeiros e do sistema carcerário no estado do Rio.

A intervenção já está em vigor, mas o decreto precisa ser aprovado pelo Congresso Nacional para continuar valendo.

Em discurso na solenidade, Temer comparou o crime organizado que atua no Rio de Janeiro a uma metástase e que, por isso, o governo federal tomou a decisão de intervir no estado.

"O crime organizado quase tomou conta do estado do Rio de Janeiro. É uma metástase que se espalha pelo país e ameaça a tranquilidade do nosso povo. Por isso acabamos de decretar neste momento a intervenção federal da área da segurança pública do Rio de Janeiro", completou Temer.

O presidente afirmou que o momento pede uma medida "extrema”. Ele ressaltou que o governo dará as respostas "firmes" para derrotar o crime organizado.

"Tomo esta medida extrema porque as circunstâncias assim exigem. O governo dará respostas duras, firmes, e adotará todas as providências necessárias para enfrentar e derrotar o crime organizado e as quadrilhas", disse Temer.

Ele também afirmou que a intervenção federal tem o objetivo de "restabelecer a ordem". O presidente informou que enviará ainda nesta sexta ao Congresso o ato e que a intervenção tem "vigência imediata".

"Não podemos aceitar passivamente a morte de inocentes e é intolerável que estejamos enterrando pais e mães de família, trabalhadores, policiais, jovens e crianças, e vendo bairros inteiros sitiados, escolas sob a mira 
de fuzis e avenidas transformadas em trincheiras", disse Temer. "Por isso, chega, basta. Nós não vamos aceitar que matem nosso presente nem continuem a assassinar o nosso futuro", concluiu.

\section{ANEXo 2: NOTÍCIA SOBRE CONFRONTO ENTRE POLÍCIA MILITAR E CIVIL}

Relembre casos de conflitos entre as polícias Civil e Militar do Tocantins[iv]

Os comandos da Polícia Civil e da Polícia Militar do Tocantins estão precisando lidar com a repercussão da morte do sargento Gustavo Teles e da prisão do sargento Edson Viana. Os dois são suspeitos de participar de duas execuções e uma tentativa de homicídio em Gurupi (TO). Teles acabou morto e Viana ficou ferido durante uma abordagem de policiais civis que investigavam o caso.

O caso está longe de ser um conflito isolado. As duas forças de segurança possuem um histórico de situações em que acabaram entrando em confronto ao invés de trabalhar juntas.

Em abril de 2017 um vídeo que mostra um grupo de policiais militares (PMs) fortemente armados invadindo uma delegacia em Paraíso do Tocantins ganhou repercussão. O delegado da época, Cassiano Oyama, disse que se tratava de uma tentativa de intimidação por uma investigação aberta contra dois militares por tráfico de drogas.

Em outubro do ano passado, em Guaraí, o delegado Marivan da Silva Souza foi baleado por PMs após ser confundido com um criminoso. Os militares estavam na cidade fazendo buscas após um assalto a um carro forte. Por sorte, Souza sobreviveu, mas perdeu parte de uma orelha no caso.

Já em abril de 2018 o sargento da Polícia Militar José Maria Rodrigues de Almeida, de 50 anos, morreu após ser baleado em um bar. Ele foi abordado pelo delegado Cassiano Oyama, que tinha sido transferido de Paraíso para a delegacia de homicídios de Palmas e por agentes que o acompanhavam. A versão dos policiais civis é de que ele teria reagido a uma abordagem, o caso ainda não está em andamento.

Para o especialista em segurança pública Tarsis Barreto, as situações poderiam ser evitadas com investimentos em tecnologia e efetivo.

"Especificamente em relação à Polícia Militar, nós temos um déficit neste quadro. O número de praças, de soldados, de cabos é muito pequeno. No âmbito da Polícia Civil, o que é necessário fazer é melhorar a capacidade de investigação, melhorar a inteligência policial”, diz ele.

O governo do estado disse que as polícias estão unidas no combate à criminalidade e enumerou oito situações em que as forças de segurança atuaram em conjunto durante alguma operação. Um dos exemplos utilizados foi o trabalho de buscas feito após a fuga de presos da Unidade de Tratamento Penal Barra da Grota, em Araguaína.

\section{ANeXo 3 - Nota DE Ensino}

Dilemas para a Implementação de Programas de Incentivo Atrelados a Desempenho em Segurança Pública

\section{Objetivos didáticos}

O caso suscita questões relacionadas à mensuração de desempenho, tema central em análises contemporâneas sobre gestão pública (Andrews, Boyne, Law, \& Walker, 2011; Boyne, 2006; Cabral, 2017; Moynihan, 2006; Perry, Engbers, \& Jun, 2009), assim como discussões sobre distorções de incentivo em organizações (Holmstrom \& Milgrom, 1991) em meio a esquemas de programas de incentivo para funcionários públicos (Burgess, Propper, Ratto, \& Tominey, 2017; Heinrich \& Marschke, 2010).

O caso pode ser utilizado para atingir alguns objetivos de aprendizagem, dentre eles compreender os fatores associados à conformação de indicadores de desempenho, analisar os dilemas relativos à mensuração de 
desempenho, avaliar a ocorrência de problemas de incentivos em organizações e discutir eventuais remédios para mitigá-los e justificar as escolhas realizadas pelos gestores no processo de mensuração de desempenho no âmbito da gestão pública. Além do binômio incentivos-desempenho, a depender do instrutor, o caso pode possibilitar discussões sobre arranjos de governança colaborativa entre órgãos governamentais, tema de trabalhos como os de Agranoff e McGuire (2004) e Saz-Carranza e Ospina (2010), de maneira a identificar desafios para a colaboração entre organismos públicos. Tais discussões são particularmente relevantes em setores complexos, como a área de segurança.

Com variações no nível de profundidade do debate e nas análises realizadas, o caso pode ser aplicado a alunos de graduação e pós-graduação (lato e stricto sensu) em cursos da área de Estratégia, Gestão Pública, ou Políticas Públicas. O caso traz diversas oportunidades para discussão das potencialidades e dos limites de sistemas de desempenho no setor público, incluindo disfunções de programas de incentivo, pertinência de recompensas pecuniárias, escolha entre incentivos individuais ou em grupo, problemas de mensuração, bem como estratégias para lidar com reações contrárias a essas iniciativas.

\section{Questóes para discussão}

O caso apresenta possibilidades de discussão em plenária na sala de aula ou por pequenos grupos de alunos. Seguem algumas propostas de questões a serem exploradas.

a) Sobre mensuração de desempenho

Possíveis questões sobre a escolha de indicadores estratégicos de violência.

1. As metas da segurança pública devem considerar indicadores finalísticos de violência ou indicadores de esforço dos policiais? Por quê?

2. No caso de indicadores de esforço dos policiais, como justificar o pagamento de bônus se houver aumento da criminalidade?

3. No caso de indicadores finalísticos, quantos e quais crimes devem ser considerados? Os pesos devem ser os mesmos? Por quê?

4. O que pode justificar alteração das metas após a sua definição inicial?

Os alunos devem lembrar-se que diferentes setores da população podem priorizar a atenção dada a diferentes tipos de crime (mulheres podem estar mais preocupadas com estupros, empresários podem estar preocupados com o roubo de cargas, etc.), porém, considerar um número elevado de tipos de crime seria um risco para a gestão do SIM, pois aumentaria o nível de complexidade para o cálculo e poderia engendrar problemas de manipulação de métricas e múltiplas tarefas (Holmstrom \& Milgrom, 1991; Payne \& Roberts, 2010). Outro fato relevante é que, com um grande número de metas, os policiais poderiam não compreender claramente como suas metas seriam calculadas e atingidas.

Por outro lado, dado que muitos agentes públicos podem questionar a penalização que sofrem quando não atingem as metas finalísticas por fatores aleatórios que não estão sob sua influência, o caso pode servir de base para discutir o conhecido informativeness principle (Hölmstrom, 1979). Especificamente na atividade policial, os alunos podem vislumbrar atividades que estão sob controle direto da polícia, e que, portanto, refletem o esforço dos policiais, tais como o número de prisões, o volume de apreensões de armas e drogas, ou ainda o número de inquéritos policiais concluídos, fazendo o necessário cotejo com indicadores finalísticos para os quais a relação entre esforço e desempenho não é totalmente isenta de fatores externos. Para os formuladores do programa, definir metas utilizando os dados de esforço poderia acarretar em um degaste da legitimidade pública do programa, pois os policiais poderiam bater metas mesmo com o aumento de crimes.

Optou-se, no Rio de Janeiro, por focar em indicadores finalísticos da ocorrência criminal, como homicídios e roubos. Além disso, optou-se por focar em indicadores mais relevantes, conforme um critério de impacto na sensação de insegurança da população. Era primordial que esses indicadores fizessem sentido para uma adesão massiva dos atores responsáveis pela sua operacionalização, os próprios policias. Pode-se também explorar o 
motivo dos pesos diferentes adotados no Rio de Janeiro. Por se considerar que a vida humana é a prioridade máxima, a meta de redução dos homicídios recebeu o maior peso.

Os alunos, com o auxílio eventual do professor, devem lembrar-se que as atividades da Polícia Civil e Militar são muito distintas entre si e que ainda há diferenças relevantes na estrutura de cada uma dessas organizações. Por exemplo, na Polícia Militar o Esquadrão Antibombas tem uma atuação muito diferente do Batalhão que patrulha a área central de uma grande cidade.

Sobre a alteração de indicadores, é interessante explorar como, no Rio de Janeiro, a inclusão das mortes por ação policial no cálculo da letalidade violenta, por exemplo, gerou polêmica. Segundo alguns policiais fluminenses, essa mudança era um desincentivo ao enfrentamento com criminosos, pois se algum criminoso morresse, dificultaria o atingimento das metas policiais.

\section{Possíveis questões sobre a escolha de nível de análise.}

\section{As metas devem ser individuais ou coletivas? Por quê?}

2. As metas devem considerar as unidades organizacionais já existentes (delegacias da Polícia Civil e batalhões da Polícia Militar, por exemplo) ou devem adotar novas unidades como as AISPs criadas pelo sistema de metas do Rio de Janeiro? Por quê?

3. O que fazer com unidades que fogem à regra da organização territorial (batalhões de choque e cavalaria atuam em qualquer lugar do estado, quando requisitados, por exemplo)

Havia a opção de metas individuais ou coletivas. Além disso, deveria haver metas diferentes para a Polícia Civil e para a Polícia Militar? Haveria variação conforme a patente (nível hierárquico) dos policiais?

No caso de metas individuais, há relativa dificuldade de mensuração que deve ser pontuada, sobretudo se forem adotadas metas finalísticas de criminalidade. No caso de metas coletivas, há o problema de free riders que deve ser apontado. Nessa linha, o professor pode explorar como minimizar o problema decorrente da diminuição do esforço em esquemas de incentivos em grupo (Kandel \& Lazear, 1992), algo que vai além do setor público.

Caso adote-se as unidades organizacionais existentes, existe a vantagem de uma equipe que se conhece mais e com uma cultura e valores organizacionais compartilhados. Essa alternativa, no entanto, contribui menos para a integração das diferentes forças policiais. Caso a opção seja por bônus baseados em novas unidades organizacionais, como forma de promover maior integração entre as polícias, como introduzir práticas de gestão que garantam a continuidade das ações?

Existe ainda uma polêmica envolvendo os critérios para a premiação de unidades que são organizadas por critérios diferentes daqueles predominantes. No caso da Polícia Militar, apesar de a maior parte dos batalhões serem organizados territorialmente, há vários batalhões especiais e especializados, que atuam quando solicitados. É o caso dos batalhões de choque ou a cavalaria. Esses batalhões não deveriam também receber uma premiação por esforço realizado? Como compatibilizar as regras para mensuração de desempenho?

\section{Possíveis questões sobre a escolha de cálculo de metas.}

1. A definição das metas deve seguir um modelo mais centralizado e técnico ou deve incluir novos atores e seguir um modelo mais descentralizado? Por quê?

A queixa do comandante de batalhão no interior do estado, apresentada no caso, mostra como policiais podem se sentir injustiçados ao terem que seguir as mesmas metas, independente das características regionais. A sensação de injustiça pode levar a uma série de distorções de incentivos, tais como comparação social e erosão moral. 
A definição centralizada das metas pode garantir mais uniformidade e alinhamento aos objetivos estratégicos do sistema, mas pode estar menos aderente à realidade de diferentes locais. Um método descentralizado de definição das metas, escutando atores locais, pode gerar mais aderência às prioridades da região, mas pode gerar grande heterogeneidade na definição das metas, causando conflitos na atribuição de bônus.

\section{Possíveis questões sobre a escolha de periodicidade de apuração das metas.}

1. As metas devem ser estipuladas por que período (mensal, bimestral, semestral, anual, por exemplo)? Por quê?

Esse debate é particularmente relevante caso os alunos tenham optado por metas finalísticas de desempenho, e não indicadores de esforço. Isso porque espera-se que as ações policiais não sejam os únicos fatores impactando a criminalidade. Dessa maneira, a apuração de metas com periodicidade muito curta (mensal ou bimestral) poderia não refletir os esforços de melhoria na atividade policial. Por outro lado, metas muito distantes (anuais, por exemplo), poderiam não gerar o incentivo cotidiano para o esforço dos policiais. Prazos muito longos podem gerar frustração nos policiais, caso os mesmos não percebam que seu esforço está sendo recompensado.

$\mathrm{Na}$ experiência fluminense havia reclamações dos policiais, por exemplo, pois alguns consideram que a ocorrência de uma chacina totalmente imprevisível em determinado período da meta poderia comprometer todo o trabalho de um semestre.

Além das questões de mensuração de desempenho apresentadas acima, há outras questões que podem ser exploradas a depender dos objetivos de aprendizagem da aula. Destacam-se, entre essas possibilidades adicionais, a variação das formas do incentivo e os arranjos de governança intergovernamental.

\section{B) Sobre sistemas de incentivo}

Sobre a variação na forma do incentivo, uma primeira discussão possível relaciona-se com a adequação de remuneração variável para as forças policiais.

Possíveis questões sobre incentivos.

1. Seria possível obter mais esforço dos policiais sem remuneração financeira e apenas com premiação simbólica?

2. Seria possível obter mais esforço dos policiais sem remuneração financeira e apenas com premiação simbólica? Há outras alternativas que geram incentivo ao esforço, como treinamentos ou promoção para os policias que atingem as metas?

3. É correto que o valor das premiações seja definido pelo governador? Quais seriam as alternativas?

4. As unidades policiais especializadas (batalhão de choque, por exemplo) que são premiadas por boas práticas deveriam receber o mesmo que as unidades que batem metas regionalizadas? Por quê?

As questões sobre incentivo devem problematizar que medidas geram os resultados esperados. A premiação monetária deve ser analisada frente à possibilidade de incentivo não monetário, pois um incentivo monetário muito forte pode acabar gerando manipulação e erosão moral, fazendo com que os policiais procurem bater as metas a qualquer custo. Essas práticas podem resultar em conflitos entre diferentes áreas da organização, que estejam disputando as premiações e que possam se sentir injustiçadas.

No Rio de Janeiro, a dificuldade em estabelecer incentivos adequados comprometeu a integração desejada entre as polícias no nível local, reunindo companhias e delegacias locais. Ainda que essa estrutura de reunióes tenha sido fundamental para o funcionamento do SIM, elas nem sempre ocorriam na periodicidade desejada. Os policiais fluminenses muitas vezes entendiam essas reuniões como uma forma de punição pelo 
não cumprimento das metas. Nos outros níveis, as reuniões eram convocadas e monitoradas pela própria Secretaria de Segurança Pública, porém, no nível mais local elas deveriam ocorrer por iniciativa dos próprios delegados e comandantes da companhia, não havendo nenhuma penalização caso elas não acontecessem.

\section{C) Sobre arranjos de governança intergovernamental}

Com relação aos arranjos de governança intergovernamental, o SIM é um exemplo do uso de incentivos para alinhar interesses de organizações que possuem historicamente uma resistência para a atuação em conjunto. Ao definir premiações em comum para áreas integradas para a segurança pública, o SIM promoveu o trabalho em conjunto das Polícias Civil e Militar.

\section{Possiveis questões sobre governança.}

1. Como institucionalizar a cooperação entre órgãos governamentais?

2. O trabalho em conjunto será sempre dependente do incentivo financeiro?

3. Como compatibilizar estruturas e processos para a cooperação?

Os desafios da cooperação intergovernamental no Brasil ainda são objeto de poucos estudos e o caso pode ser utilizado para explicitar alguns dos dilemas envolvidos nesses arranjos. No caso do Rio de Janeiro houve importantes aprendizados relacionados à necessidade de uma comunicação adequada na governança dos dois órgãos policiais. Os policiais lhe disseram que, inicialmente, quando da implantação do SIM, não havia sido realizado nenhum plano de comunicação formal, identificando os principais stakeholders e abordando as questões que geravam maior ruído de informação. Essa falta de comunicação gerou temores infundados de que o objetivo seria reduzir a autonomia das polícias. Com o passar do tempo, percebendo essa dificuldade, a Secretaria de Segurança realizou ajustes para aprimorar a comunicação ao longo da experiência com o sistema de metas. As medidas para remediar a falha inicial na comunicação do programa envolveram um intenso diálogo com atores-chave que pareciam não estar convencidos sobre os benefícios do sistema de metas.

Além disso, no Rio de Janeiro foi necessário realizar ajustes organizacionais para compatibilizar a estrutura das polícias, envolvendo a criação de cargos e alteração de certas atribuições nas polícias, de forma que para cada liderança em uma das forças policiais houvesse outra liderança de nível e jurisdição equivalentes na outra força policial. Ainda assim, as diferenças estruturais das duas polícias criavam dificuldades para o SIM, especialmente porque a estrutura da Polícia Civil é mais limitada em determinadas áreas do interior, dificultando uma efetiva colaboração em algumas AISPs.

\section{Sugestão para Plano de Ensino}

Há várias possibilidades de aplicação do caso. Considerando uma aula de aproximadamente duas horas, sugere-se que a leitura prévia do caso seja feita individualmente pelos alunos. A aula pode iniciar com uma discussão geral, em plenária, sobre vantagens e desvantagens de um sistema de mensuração de desempenho na segurança pública. Após vinte minutos dessa discussão inicial, os alunos podem iniciar o trabalho em pequenos grupos, de cinco ou seis integrantes, respondendo a três ou quatro questões selecionadas previamente e apresentadas pelo docente. Deve-se atribuir tempo suficiente para essa etapa, com debate entre os alunos sobre prós e contras de cada escolha realizada. Após aproximadamente uma hora dos debates em pequenos grupos, sugere-se a apresentação dos resultados de dois grupos selecionados aleatoriamente. O docente deve aproveitar essa oportunidade para provocar reflexões críticas sobre as opções apresentadas, incentivando a participação dos demais grupos e acrescentando, conforme tenha oportunidade, questões 
subsequentes para reflexão dos alunos. Nos últimos dez minutos de aula, sugere-se um fechamento que aborde outros dilemas apresentados nesta nota de ensino e não aprofundados durante a discussão dos alunos.

Para uma aula mais curta, com 60 minutos de duração, o instrutor pode também optar por oferecer questões mais estruturadas para guiar uma discussão sobre indicadores de desempenho. Por exemplo, no início da aula, pode projetar num slide as seguintes perguntas:

- Que tipo de indicadores Evair deveria priorizar no sistema de metas de Santa Clara? Subjetivos ou objetivos? Quais os problemas decorrentes dessas escolhas?

- Evair deve priorizar incentivos individuais ou em grupo? Por que?

- Como Evair deve definir as metas? Quais os indicadores adequados? Qual periodicidade você julga como mais adequada?

Após 10 minutos de discussão, os alunos podem ser instados a discutir, por exemplo, a diferença entre indicadores subjetivos e objetivos. $\mathrm{O}$ instrutor pode começar a discussão dessa primeira pasture com a seguinte cold call: Uma das principais metas é combater sensação de insegurança. Isso é objetivo ou subjetivo? Quais os problemas associados a isso?

Por 10 minutos as discussões podem continuar, até que os alunos, guiados pelo professor, compreendam os problemas relacionados à dificuldade de observação e mensuração e que pesquisas de percepção podem ser influenciadas por fatores externos aleatórios a depender do momento (após crimes de grande comoção, por exemplo), turvando as análises.

Em seguida o instrutor pode mover para a segunda pasture, relacionada à forma de medição de desempenho por meio da seguinte cold call: Por que não medir o desempenho de cada policial com base na opinião do supervisor imediato ou de pares (i.e. Avaliação 360)?

Após 10 minutos de discussão, os seguintes pontos poderão ser levantados:

a) Supervisores podem não se esforçar para avaliar, pois suportam custo da avaliação, mas pequena fração dos benefícios;

b) Tais práticas podem engendrar custos de influência (ou lobby) e manter a ambiguidade;

c) Os avaliadores podem não conhecer avaliados ou terem condições de observar seus esforços; ou, ainda,

d) Há grande possibilidade de propagar sentimento de injustiça por conta da discricionariedade existente.

A terceira pasture pode abordar, também por 10 minutos, as medidas objetivas de desempenho. Discussões sobre como determinar metas, se pelo desempenho passado, gerando ratchet effect, em que o agente diminui esforço atual para manipular resultados futuros, ou por análise relativa de desempenho através da comparação de unidades similares para diminuir efeito de choques aleatórios. O instrutor pode discutir a questão da avaliação externa rigorosa e os problemas relacionados ao custo de obtenção de dados e de capacidade de análise.

Por fim, na última pasture, os alunos conduzidos pelo professor podem por 15 minutos discutir os critérios para gerar bons indicadores de desempenho. O professor pode abrir o link do Guia Insper Metricis para ilustrar a discussão. Os alunos devem reconhecer que um bom indicador contém as seguintes propriedades: Possui relevância, é passível de ação por parte dos agentes, é preciso e apresenta baixo custo de medição.

Nos 5 minutos restantes o instrutor pode fazer um wrap-up sobre os pontos vistos e reforçar que a aula não se limita a atividades policiais, ou ao setor público, mas sim, a indicadores de desempenho em organizações.

\section{Indicações bibliográficas}

Há inúmeras referências para o aprofundamento dos temas abordados neste caso de ensino. Diversos autores discutem incentivos no setor público (Burgess et al., 2017; Frant, 1996; Heinrich \& Marschke, 2010). Há também análises sobre mensuração de desempenho em governos (Amirkhanyan, 2009; Boyne, 2006; De Bruijn, 2002; Propper \& Wilson, 2003). A literatura sobre governança considera arranjos entre organizações governamentais e também entre governos e organizações privadas (Agranoff \& McGuire, 2004; Ansell 
\& Gash, 2008; Bryson, Crosby, \& Stone, 2015; Klijn, Edelenbos, \& Steijn, 2010; Salamon, 2002). Para uma avaliação do SIM implementado no Rio de Janeiro, ver relatório final de pesquisa em Cabral, Firpo, Marchesini da Costa e Viotti (2016). Sobre causas da violência e políticas de segurança pública, ver Duarte et al. (2012); Nery, Peres, Cardia, Vicentin e Adorno (2012), Ingram e Marchesini da Costa (2017) e Cardoso, Ceccheto, Corrêa e Souza (2016). Sobre o histórico de violência no Brasil e Rio de Janeiro, ver Amorim (2012), Arias (2013), Caldeira e Holston (1999) e Pinto e Do Carmo (2016).

\section{REFERÊNCIAS}

Agranoff, R., \& McGuire, M. (2004). Collaborative public management: New strategies for local governments. Georgetown University Press.

Amirkhanyan, A. A. (2009). Collaborative performance measurement: Examining and explaining the prevalence of collaboration in state and local government contracts. Journal of Public Administration Research and Theory, 19(3), 523-554.

Amorim, C. (2012). Comando vermelho: a história do crime organizado. Editora Best Seller.

Andrews, R., Boyne, G., Law, J., \& Walker, R. (2011). In Strategic management and public serviceperformance. Springer.

Ansell, C., \& Gash, A. (2008). Collaborative governance in theory and practice. Journal of Public Administration Research and Theory, 18(4), 543-571.

Arias, E. D. (2013). The impacts of differential armed dominance of politics in Rio de Janeiro, Brazil. Studies in Comparative International Development, 48(3), 263-284.

Boyne, G. A. (2006). Public service performance: Perspectives on measurement and management. Cambridge University Press.

Bryson, J. M., Crosby, B. C., \& Stone, M. M. (2015). Designing and implementing cross - sector collaborations: Needed and challenging. Public Administration Review, 75(5), 647-663.

Burgess, S., Propper, C., Ratto, M., \& Tominey, E. (2017). Incentives in the public sector: Evidence from a government agency. The Economic Journal, 127(605), F117-F141.

Cabral, S. (2017). Reconciling conflicting policy objectives in public contracting: the enabling role of capabilities. Journal of Management Studies, 54(6), 823-853.

Cabral, S., Firpo, S., Marchesini da Costa, M., \& Viotti, L. (2016). Avaliação do sistema de metas e acompanhamento dos resultados da segurança pública no estado do Rio de Janeiro. (p. 19). Fundação Brava.

Caldeira, T. P., \& Holston, J. (1999). Democracy and violence in Brazil. Comparative Studies in Society and History, 41(04), 691-729.

Cardoso, F. L. M. G., Cecchetto, F. R., Corrêa, J. S., \& Souza, T. O. de. (2016). Homicides in Rio de Janeiro, Brazil: an analysis of lethal violence. Ciencia \& Saude Coletiva, 21(4), 1277-1288.

De Bruijn, H. (2002). Performance measurement in the public sector: strategies to cope with the risks of performance measurement. International Journal of Public Sector Management, 15(7), 578-594.

Duarte, E. C., Garcia, L. P., Freitas, L. R. S. de, Mansano, N. H., Monteiro, R. A., \& Ramalho, W. M. (2012). Ecological association between characteristics of the municipalities and the risk of homicide in adult males aged 20 to 39 in Brazil: 1999-2010. Ciencia \& Saude Coletiva, 17(9), 2259-2268.

Frant, H. (1996). High-powered and low-powered incentives in the public sector. Journal of Public Administration Research and Theory, 6(3), 365-381.

Heinrich, C. J., \& Marschke, G. (2010). Incentives and their dynamics in public sector performance management systems. Journal of Policy Analysis and Management, 29(1), 183-208.

Hölmstrom, B. (1979). Moral hazard and observability. The Bell Journal of Economics, 1(1), 74-91.

Holmstrom, B., \& Milgrom, P. (1991). Multitask principal-agent analyses: Incentive contracts, asset ownership, and job design. JL Econ. \& Org., 7(1), 24-52. 
Ingram, M. C., \& Marchesini da Costa, M. (2017). A spatial analysis of homicide across Brazil's municipalities. Homicide Studies, 21(2), 87-110.

Kandel, E., \& Lazear, E. P. (1992). Peer pressure and partnerships. Journal of Political Economy, 100(4), 801-817.

Klijn, E.-H., Edelenbos, J., \& Steijn, B. (2010). Trust in Governance Networks Its Impacts on Outcomes. Administration \& Society, 42(2), 193-221.

Moynihan, D. P. (2006). What do we talk about when we talk about performance? Dialogue theory and performance budgeting. Journal of Public Administration Research and Theory, 16(2), 151-168.

Nery, M. B., Peres, M. F. T., Cardia, N., Vicentin, D., \& Adorno, S. (2012). Spatial regimes: dynamics of intentional homicides in the city of São Paulo between 2000 and 2008. Revista Panamericana de Salud Pública, 32(6), 405412.

Payne, A. A., \& Roberts, J. (2010). Government Oversight of Public Universities: Are Centralized Performance Schemes Related to Increased Quantity or Quality? The Review of Economics and Statistics, 92(1), 207-212.

Perry, J. L., Engbers, T. A., \& Jun, S. Y. (2009). Back to the Future? Performance - Related Pay, Empirical Research, and the Perils of Persistence. Public Administration Review, 69(1), 39-51.

Pinto, R. F., \& Do Carmo, M. S. (2016). The pacifying police units of the State of Rio de Janeiro (UPPs): Incremental innovation or police reform? Public Administration and Development, 36(2), 121-131.

Propper, C., \& Wilson, D. (2003). The use and usefulness of performance measures in the public sector. Oxford Review of Economic Policy, 19(2), 250-267.

Salamon, L. M. (2002). The tools of government: A guide to the new governance. Oxford University Press.

Saz-Carranza, A., \& Ospina, S. M. (2010). The behavioral dimension of governing interorganizational goal-directed networks - Managing the unity-diversity tension. Journal of Public Administration Research and Theory, 21(2), $327-365$.

\section{Notas}

[i]CABRAL, Sandro; FIRPO, S.; MARCHESINI DA COSTA, M.; VIOTTI, L. T. Avaliação do sistema de metas e acompanhamento dos resultados da segurança pública no estado do Rio de Janeiro. Fundação Brava. 2016.

[ii]Ver, por exemplo, INGRAM, Matthew C.; MARCHESINI DA COSTA, Marcelo. A spatial analysis of homicide across Brazil's municipalities. Homicide studies, v. 21, n. 2, p. 87-110, 2017.

[iii]Por Guilherme Mazui, Bernardo Caram e Roniara Castilhos, G1 e TV Globo - Brasília. Trecho de reportagem recuperado de: https://g1.globo.com/politica/noticia/temer-assina-decreto-de-intervencao-federal-na-seguranca-do-rio-de-janeiro.ghtml

[iv]Por TV Anhanguera. Recuperado de: https://g1.globo.com/to/tocantins/noticia/2018/10/24/relembre-casos-de-conflitosentre-as-policias-civil-e-militar-do-tocantins.ghtml

\section{BY-NC-ND}

